\title{
Hypersomnia Secondary to Pituitary Tumor
}

\author{
Ki-Hwan Ji \\ Department of Neurology, Busan Paik Hospital, Inje University College of Medicine, Busan, Korea
}

\author{
뇌하수체종양에 의한 과다수면
}

지기환

인제대학교 의과대학 부산백병원 신경과학교실

A 17-year-old girl visited the sleep clinic because of excessive daytime sleepiness (EDS) for five years. She went to bed at 22:00 and woke up at 10:00. Recently sleepiness got worse. She had no cataplexy, sleep hallucination or sleep paralysis. She had been taking a nap about 3-4 hour, but she had not felt refreshed. She denied of snoring or witnessed apnea. Epworth Sleepiness Scale was 17. She reported that visual acuity in the left eye has decreased since six months ago. In medical history, she had an irregular menstrual cycle and complained of amenorrhea recently. Central hypersomnia due to medical disorder should be excluded considering decreased visual acuity and amenorrhea. For exclusion of central hypersomnia, brain MRI was taken (Fig. 1). Patients with sustained damage to the hypothalamic/pituitary regions develop EDS regard- less of the etiology. ${ }^{1}$ Increased daytime somnolence or sleep disturbances may continue despite tumor removal. ${ }^{2,3}$ Physicians should give an attention to the sleep symptoms to prevent the delay in the diagnosis and effective intervention.

\section{REFERENCES}

1. Rosen GM, Bendel AE, Neglia JP, Moertel CL, Mahowald M. Sleep in children with neoplasms of the central nervous system: case review of 14 children. Pediatrics 2003;112(1 Pt 1):e46-e54.

2. Biermasz NR, Joustra SD, Donga E, et al. Patients previously treated for nonfunctioning pituitary macroadenomas have disturbed sleep characteristics, circadian movement rhythm, and subjective sleep quality. JClin Endocrinol Metab 2011;96:1524-1532.

3. Snow A, Gozal E, Malhotra A, et al. Severe hypersomnolence after pituitary/hypothalamic surgery in adolescents: clinical characteristics and potential mechanisms. Pediatrics 2002;110:e74.

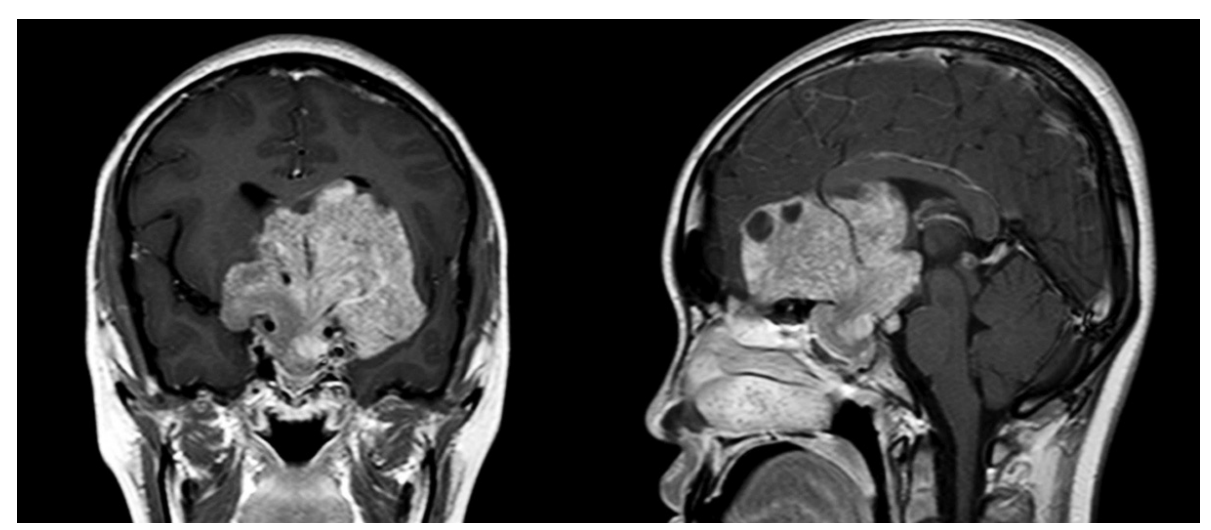

Figure 1. Contrast-enhanced T1-weighted spin-echo coronal and sagittal images. A large pituitary tumor was located in the sellar, suprasellar, both cavernous sinus, hypothalamic, frontal and third ventricular area. A tumor was extra-axial, lobular and heterogeneous with cystic change and hemorrhage. The optic chiasm was not visualized.

\section{Received November 11, 2015 / Revised December 1, 2015 / Accepted December 4, 2015}

Address for correspondence

Ki-Hwan Ji, MD, Department of Neurology, Busan Paik Hospital, Inje University College of Medicine, 75 Bokji-ro, Busanjin-gu, Busan 47392, Korea Tel: +82-51-890-8769, Fax: +82-51-890-6130, E-mail: kihwanji@gmail.com

This is an Open Access article distributed under the terms of the Creative Commons Attribution Non-Commercial License (http://creativecommons.org/licenses/by$\mathrm{nc} / 3.0$ ) which permits unrestricted non-commercial use, distribution, and reproduction in any medium, provided the original work is properly cited. 